\title{
ADAPTATION AND CONSERVATION OF THE SRI MANGANTI HALL AT YOGYAKARTA'S KERATON PALACE COMPLEX
}

\author{
${ }^{1}$ Clarissa Jesslyn Soma. ${ }^{2}$ Dr. Ir. Alwin S. Sombu, M.T. \\ I Student in the Bachelor's (S-1) Study Program in Architecture \\ at Parahyangan Catholic University \\ 2 Senior lecturer in the Bachelor's (S-1) Study Program in Architecture \\ at Parahyangan Catholic University
}

\begin{abstract}
Yogyakarta's Keraton palace forms part of the Special Region of Yogyakarta (DIY) that has architectural values of high standing. Apart from this, the hall called Sri Manganti takes specific pride of place in this palace. The purpose of this research project is to reveal these architectural aspects through establishing their cultural significance, meaningful architectural elements and the conservational measures applied to this particular hall. The theories employed for this piece of research include the Capon theory, the Orbasli theory, the Feilden theory, the Forsythe theory, and finally the Javanese Tradition Architectural theory. The methods used consist of the descriptive and the qualitative method along with the architectural approach to the matter of the building's form and function, and the local conservation of the various cultural meanings.

The cultural significance of the Sri Manganti hall lies in the application of the Javanese architectural concept of Joglo Mangkurat (referring to the roof's steep upper section) along with the hanging structure known as Lambung Gantung, aesthetic appreciation of Javanese culture and tradition and exhibition and performance of Javanese art. The architectural and aesthetic values can be discerned in its architectural components consisting of the fundament, floor, poles/pillars, supporting and upper wooden beams called ander \& molo, ceiling, roof, various decorations and the general lay-out.

A valuable building like this has apparently suffered from loss of quality in the components of its construction. This decline in quality could have been caused by the impact of the tropical climate, faulty maintenance and certain questionable human measures taken. On the other hand, it turns out that the change of function into an exhibition venue for art has actually brought added value in terms of the building's usefulness. This building falls under the essential buildings that make up the Keraton palace, so its general condition needs to be properly maintained, both with the measures taken to adapt and conserve it for the future.
\end{abstract}

Keywords : architectural value, aesthetic value, conservation, adaptation, preservation

\section{ADAPTASI DAN PRESERVASI BANGSAL SRI MANGANTI KOMPLEKS KERATON YOGYAKARTA}

\author{
${ }^{1}$ Clarissa Jesslyn Soma. ${ }^{2}$ Dr. Ir. Alwin S. Sombu, M.T. \\ ${ }^{1}$ Mahasiswa S1 Program Studi Arsitektur Universitas Katolik Parahyangan. \\ 2 Dosen Pembimbing S1 Program Studi Arsitektur Universitas Katolik Parahyangan.
}

\begin{abstract}
Abstrak- Keraton Yogyakarta merupakan bagian dari Daerah Istimewa Yogyakarta yang memiliki nilai arsitektur yang dikenal baik. Di samping itu, bangsal Sri Manganti memiliki keistimewaan di dalam Keraton Yogyakarta. Tujuan dari penelitian ini adalah untuk mengungkap aspek - aspek arsitektur melalui makna kultural, elemen arsitektur yang signifikan, dan tindakan konservasi yang digunakan pada Bangsal Sri Manganti. Teori yang digunakan pada penelitian ini adalah teori Capon, teori Orbasli, teori Feilden, teori Forysth, dan teori Arsitektur Tradisional Jawa. Metode yang digunakan di dalam penelitian ini adalah metode deskriptif dan metode kualitatif dengan pendekatan arsitektural dalam hal bentuk serta fungsi bangunan, dan juga pelestarian makna - makna kultural setempat.

Makna kultural dari Bangsal Sri Manganti adalah penerapan arsitektur Jawa Joglo Mangkurat beserta dengan struktur Lambang Gantung, apresiasi estetika kultur dan budaya Jawa, serta kegiatan pertunjukan seni Jawa. Nilai arsitektural dan estetika dapat terlihat pada komponen arsitekturnya yang terdiri dari umpak, lantai, tiang,
\end{abstract}

\footnotetext{
${ }^{1}$ Corresponding Author: clarissa.jsoma@gmail.com
} 
ander dan molo, plafon, atap, ragam hias dan tata ruangnya. Bangunan yang bernilai ini tampaknya telah mengalami penurunan mutu pada komponen - komponen bangunannya. Penurunan mutu ini dapat disebabkan oleh pengaruh iklim, kesalahan perawatan, dan tindakan manusia. Di sisi lain, ternyata perubahan fungsi menjadi tempat pertunjukkan seni pada bangunan Bangsal Sri Manganti justru memberikan nilai tambah terhadap nilai guna bangunan. Bangunan ini termasuk bangunan penting yang berada di dalam keraton, sehingga perlu dijaga kondisinya baik dengan tindakan adaptasi dan preservasi..

Kata-kata kunci : nilai arsitektural, nilai estetika, konservasi, adaptasi, preservasi

\section{PENDAHULUAN}

\subsection{LATAR BELAKANG PENELITIAN}

Daerah Istimewa merupakan wilayah tertua kedua di Indonesia, setelah Jawa Timur. Keraton Yogyakarta yang merupakan bagian dari Daerah Istimewa Yogyakarta merupakan salah satu peninggalan arsitektur tradisional yang masih terjaga hingga saat ini. Keraton Yogyakarta telah berdiri kurang lebih 260 tahun. Kompleks Yogyakarta merupakan bangunan yang sangat penting yang memiliki nilai- nilai budaya Jawa dan juga merupakan peninggalan Arsitektur Jawa. Bangsal Sri merupakan bangunan yang berada di dalam Kompleks Keraton Yogyakarta ( figur 1).

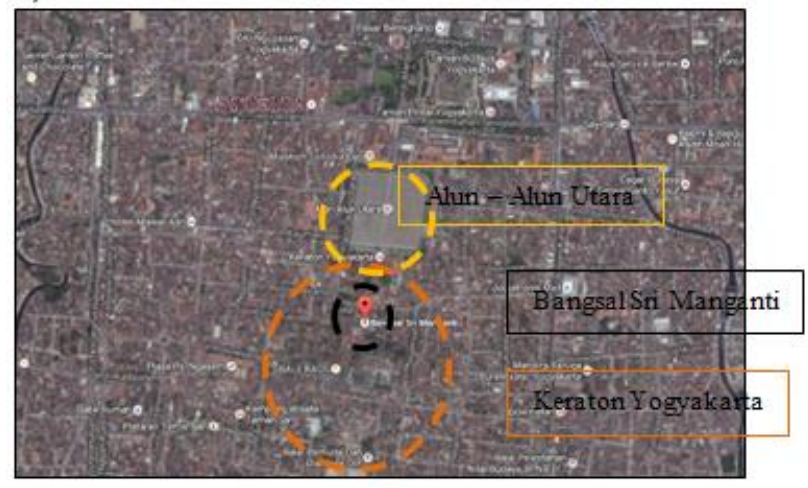

Figur 1. Peta Lokasi Bangsal Sri Manganti (Sumber: www.maps.google.com, Agustus 2016)

Keberadaan Keraton Yogyakarta sangat mempengaruhi keberadaan dan pembangunan arsitektur bangunan di sekitarnya. Tata fisik kota Kasultanan Yogyakarta telah memiliki komponen utama kota dan tata ruang yang berorientasi ke utara dan selatan. Luas area Keraton sekitar $14.000 \mathrm{~m}^{2}$. Bangsal Sri Manganti berada di Pelataran Sri Manganti. Pelataran ini merupakan halaman transisional menuju ke pelataran kedhaton dari arah utara. Menurut K.P.H. Brongtodiningrat (1978: 22), bahwa Bangsal Sri Manganti ini menggambarkan saat manusia akan menginjak alam barzah.

Bangsal Sri Manganti dipergunakan untuk pertunjukkan kebudayaan yang istimewa. Hal ini menjadikan Bangsal Sri Manganti ini berfungsi penting di dalam kegiatan kebudayaan dan hubungan dengan anggota dari luar Keraton Yogyakarta (figur 2).
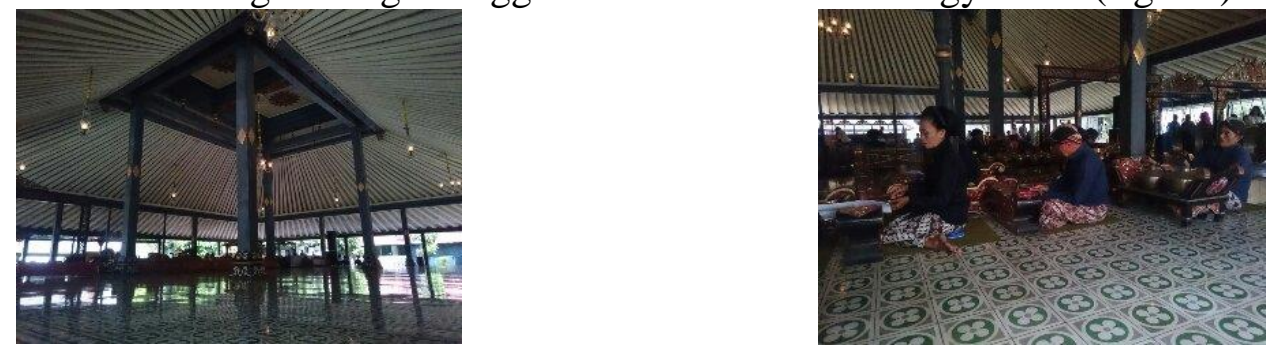

Figur 2. Bangsal Sri Manganti dan Kegiatan pada Bangsal Sri Manganti (Sumber: Dokumentasi Pribadi, Agustus 2016) 
Sebagai tempat kegiatan kebudayaan dan objek wisata,maka Bangsal Sri Manganti seharusnya dirawat dan dijaga dengan baik. Namun karena kurangnya kepekaan masyarakat terhadap warisan asli Indonesia tidak jarang bangunan tersebut telah memiliki kerusakan dan kerapuhan di beberapa bagian.

Oleh karena itu penelitian ini dilakukan agar meninjau adanya kerusakan pada Bangsal Sri Manganti dan tindakan konservasi apa yang dilakukan dan paling cocok digunakan di dalam bangunan ini, sehingga nilai dan makna Arsitektur Jawa tetap terjaga dengan baik.

\subsection{PERUMUSAN MASALAH}

Sesuai dengan permasalahan penelitian yang telah diuraikan, pertanyaan penelitian yang diajukan adalah :

a. Apa makna kultural yang dimiliki oleh Bangsal Sri Manganti, sehingga bangunan ini harus tetap dipertahankan?

b. Apa saja elemen signifikan pada Bangsal Sri Manganti sehingga patut untuk dikonservasi?

c. Tindakan konservasi apakah yang tepat digunakan untuk menjaga elemen signifikan pada Bangsal Sri Manganti?

\subsection{TUJUAN PENELITIAN}

Tujuan Penelitian dari penelitian ini berdasarkan perumusan diatas adalah:

1. Mengetahui makna kultural yang dimiliki oleh Bangsal Sri Manganti, sehingga perlu untuk dilakukan tindakan konservasi.

2. Mengetahui elemen signifikan pada Bangsal Sri Manganti sehingga patut untuk dikonservasi.

3. Mengetahui tindakan konservasi untuk menjaga elemen signifikan pada Bangsal Sri Manganti.

\subsection{METODOLOGI PENELITIAN}

Metode yang digunakan di dalam penelitian ini merupakan metode kualitatif, komparatif, dan deskriptif. Metode kualitatif berupa pencarian studi literatur, observasi aktif, pasif, serta pengambilan data- data dokumentasi berupa foto dan gambar- gambar lain.

\subsection{LOKASI PENELITIAN}
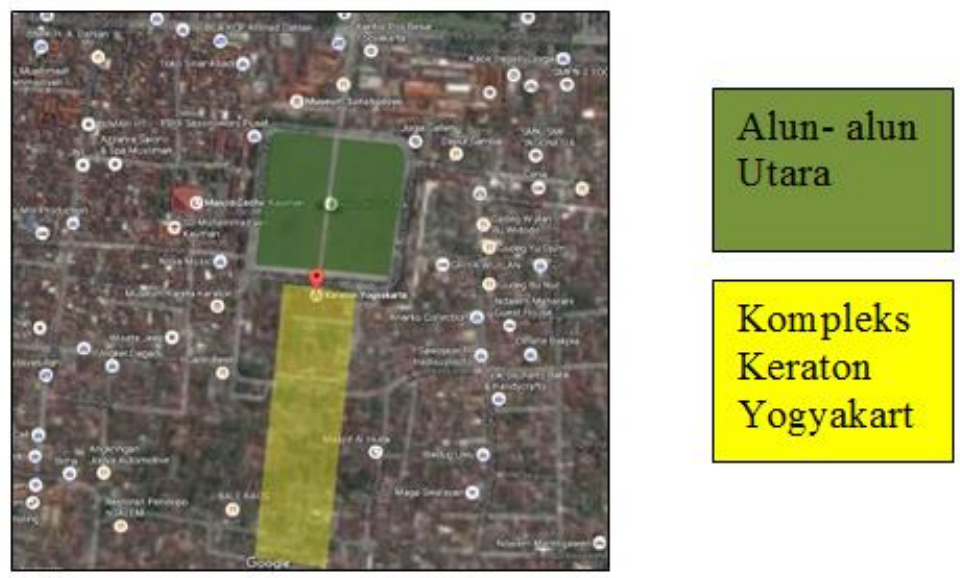

Figur 3. Gambar Lokasi Penelitian (Sumber: Google Maps, November 2016) 


\subsection{KERANGKA PENELITIAN}

\section{Latar Belakang:}

1. Unsur dan budaya Arsitektur Jawa diterapkan di dalam bentuk, struktur, dan juga ornamen bangunan- bangunan di dalam Kompleks Keraton Yogyakarta.

2. Bangsal Sri Manganti merupakan salah satu bangunan inti Keraton yang masih difungsikan secara teratur.

3. Perubahan fungsi, kurangnya perawatan dan perbaikan pada bangunan, menjadikan Bangsal Sri Manganti memiliki kerusakan di beberapa bagian.

\section{Rumusan Masalah:}

Bangsal Sri Manganti merupakan bangunan bersejarah yang memiliki nilai arsitektur, nilai estetika, dan nilai guna bangunan Jawa telah mengalami beberapa kerusakan.

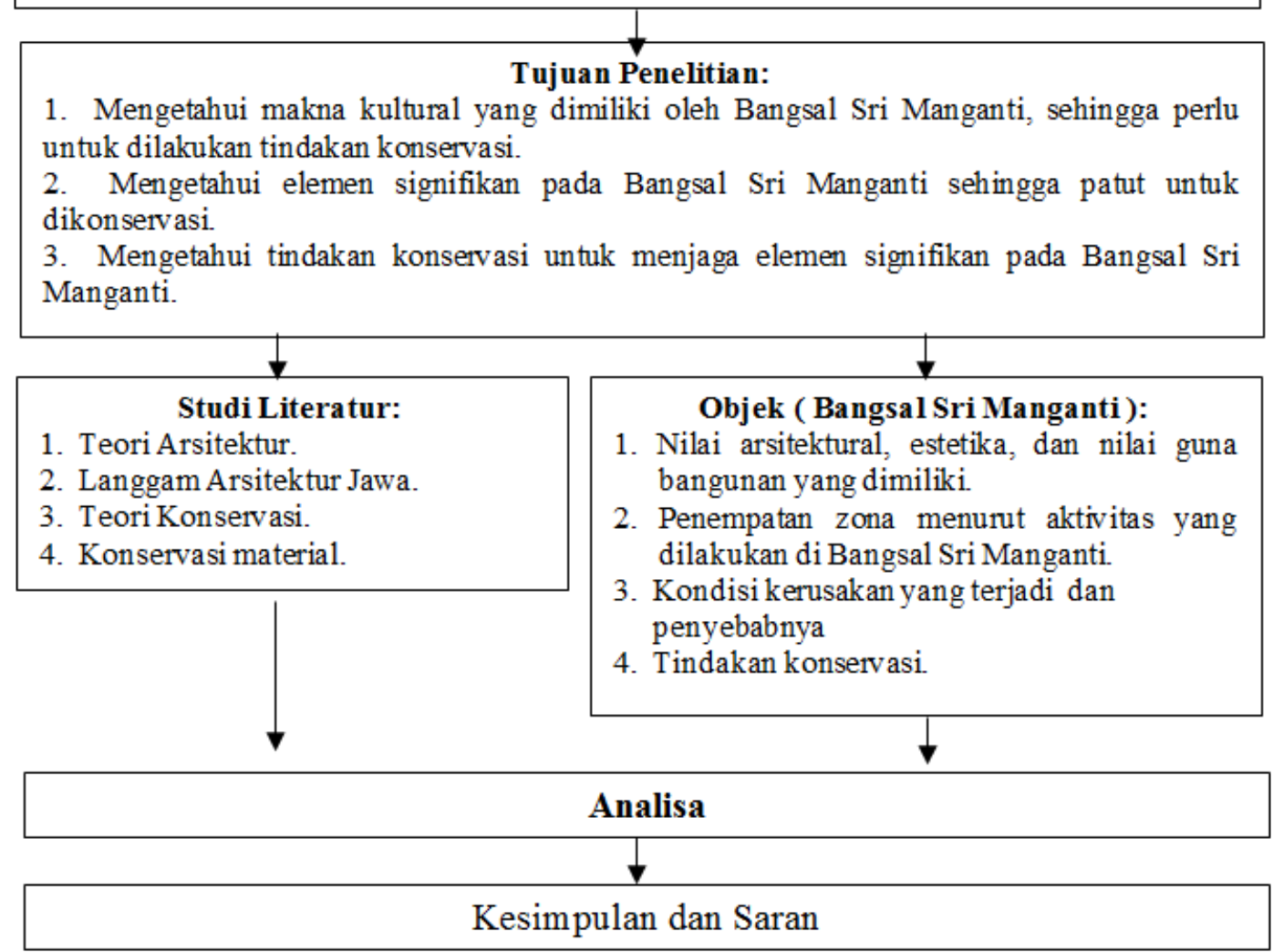

Figur 4. Diagram Kerangka Penelitian

(Sumber: Dokumentasi Pribadi, November 2016)

\section{ANALISA}

\subsection{TEORI DAN PEDOMAN KONSERVASI}

Berdasarkan Kamus Besar Bahasa Indonesia, Konservasi merupakan tindakan pemeliharaan dan perlindungan sesuatu secara teratur untuk mencegah kemusnahan dan kerusakan dengan jalan mengawetkan, pengawetan, pelestarian.

Sebelum melakukan upaya konservasi pada suatu bangunan, kita harus mengetahui makna kultural yang terdapat pada bangunan tersebut sehingga layak untuk dikonservasi. Makna kultural terdiri dari banyak nilai. Nilai yang akan dibahas terdiri dari nilai arsitektural, nilai estetika, dan nilai guna bangunan.

Setelah mengkaji makna kultural, kita harus mengetahui kondisi makna tersebut dan mencari cara untuk mengatasi penurunan mutu pada nilai tersebut. 


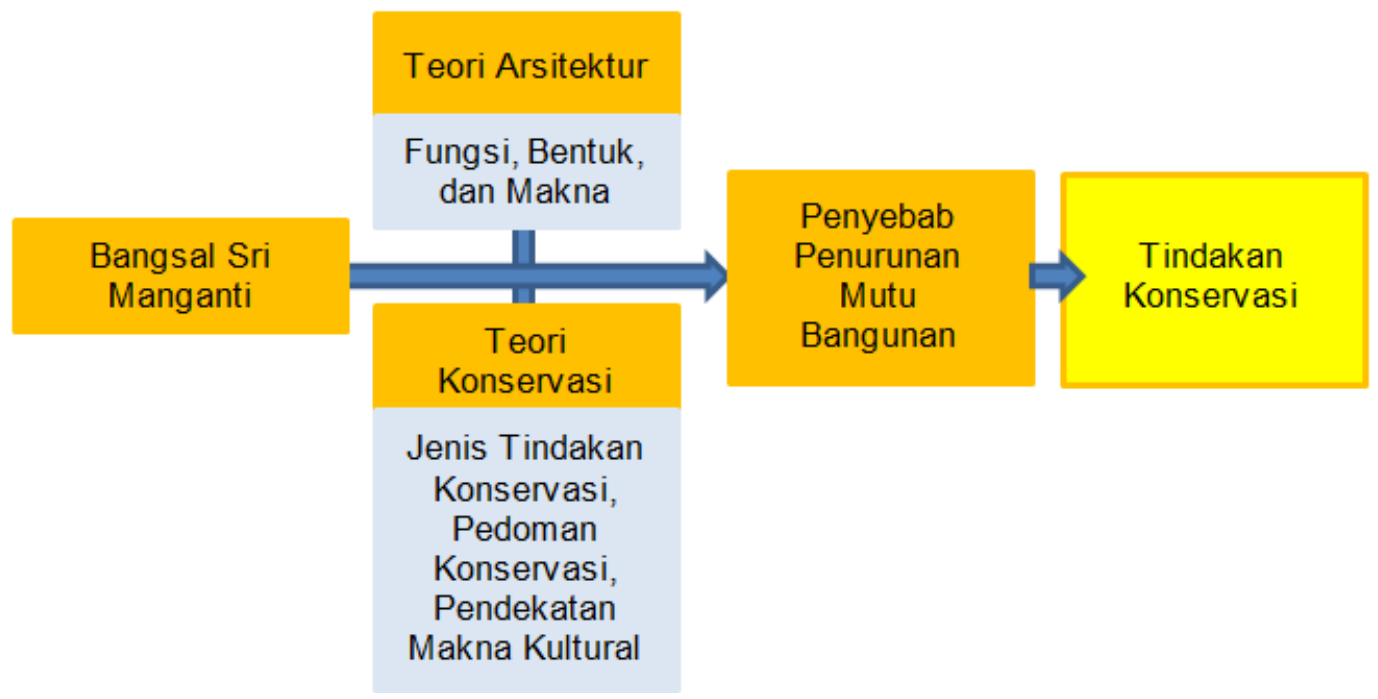

Figur 5. Diagram Kerangka Dasar Teori (Sumber: Dokumen Pribadi, November 2016)

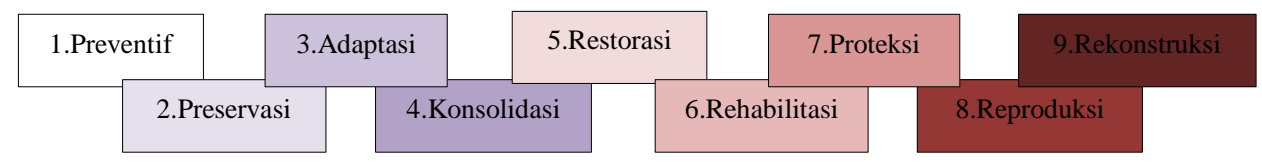

Figur 6. Urutan Tindakan Konservasi Sesuai dengan

Tindakan Konservasi pada Bangunan

(Sumber: Dokumen Pribadi, Oktober 2016)

Keterangan : Semakin tinggi angka dan semakin gelap warna, semakin tinggi tingkat keruasakan pada bangunan .

\section{Pendekatan Nilai Konservasi}

Nilai- nilai yang terdapat di dalam makna kultural dapat diklasifikasikan ke dalam 2 jenis nilai, yakni nilai nyata, yang langsung terkait dengan nilai yang terdapat pada bangunan bersejarah dan nilai yang kurang nyata, yang berkaitan dengan aspek emosi, simbol dan spiritual. Setelah melakukan pengkajian, terdapat 3 nilai menarik yang dapat dibahas mengenai Bangsal Sri Manganti. Nilai tersebut, yang merupakan warisan kultural tersebut, yakni:

Nilai Arsitektural dan Nilai Estetika. Di samping itu Nilai Guna Bangunan juga terdapat pada Bangsal Sri Manganti.

\subsection{BANGSAL SRI MANGANTI}

\section{Data Bangsal Sri Manganti}

Nama objek : Bangsal Sri Manganti

Lokasi : Daerah kedhaton, Kompleks Keraton Yogyakarta, Jl.Rotowijayan

1, Yogyakarta

Tahun didirikan : 1769

Fungsi :Sebagai tempat pertunjukkan kebudayaan Jawa

Bentuk : Joglo Mangkurat

Orientasi : Utara- Selatan. 


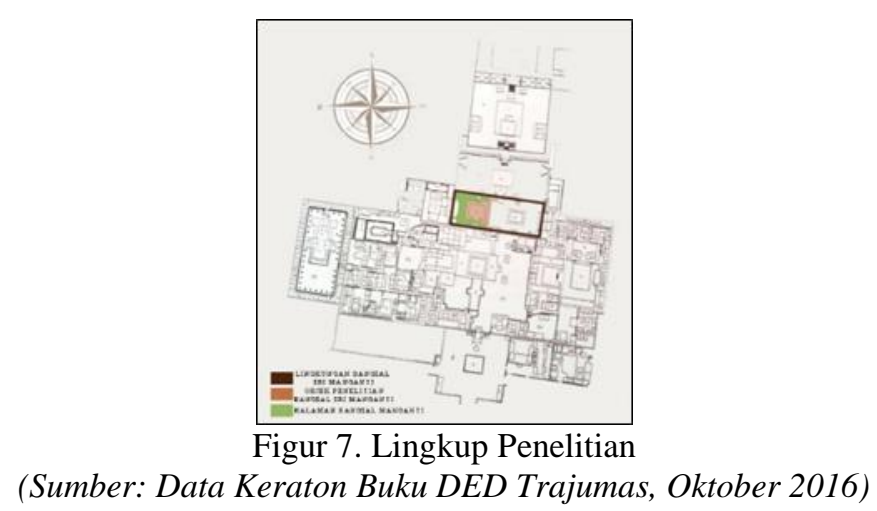

\section{Arsitektur Bangsal Sri Manganti}

\section{Bangunan Joglo Mangkurat dengan struktur Lambang Gantung}

Bangsal Sri Manganti merupakan Bangunan Joglo Mangkurat berukuran $24 \mathrm{~m}$ x $21 \mathrm{~m}$. Bangsal ini disangga oleh 44 tiang dan 4 diantaranya merupakan saka guru. Struktur bangunan ini menggunakan sistem umpak pada bagian pondasi, tumpeng sari pada bagian balok, dan atap dengan lambang gantung (figur 8).
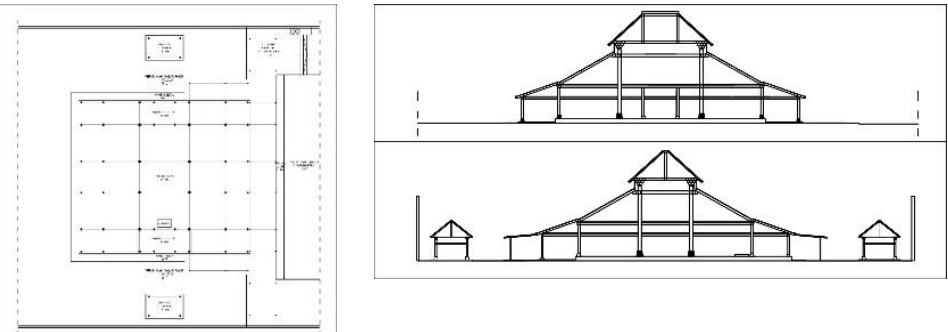

Figur 8. Denah dan Potongan Bangsal Sri Manganti

(Sumber: Dokumen Pribadi, November 2016)

Elemen Bangsal Sri Manganti merupakan campuran dari elemen garis dan elemen bidang. Elemen garis terdapat pada penempatan kolom- kolom tanpa dinding yang memberikan kesan pengulangan garis yang memberikan irama. Elemen bidang terdapat pada bagian penutup atap yang merupakan gabungan dari penempatan balok secara menerus dengan jarak yang kecil, selain memberikan kesan elemen bidang, penempatan balok ini memberikan kekuatan dan kekakuan pada Bangunan Joglo ini. (gambar 7.). Warna dominan pada Bangunan ini adalah abu tua, yang melambangkan ketenangan dan kesederhanan. Warna hitam memiliki arti keabadian.
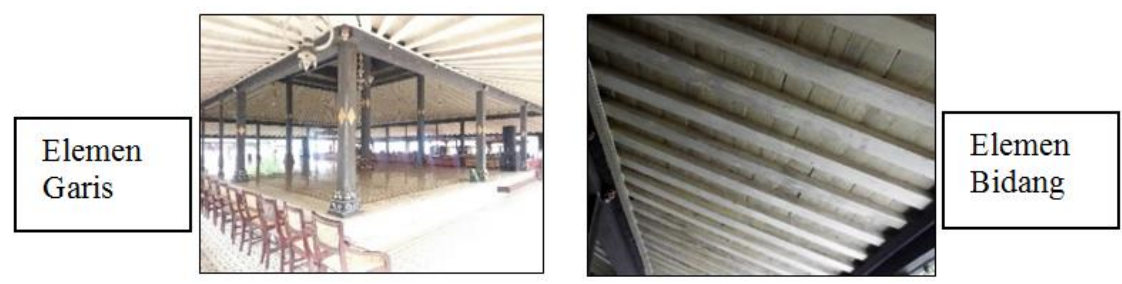

Figur 9. Lingkup Penelitian

(Sumber: Data Keraton Buku DED Trajumas, Oktober 2016)

\section{Komponen Bangunan}

\section{a. Lantai}

Lantai merupakan bagian dari Bangsal Sri Manganti yang mengandung bentuk istimewa. (figur 10). 


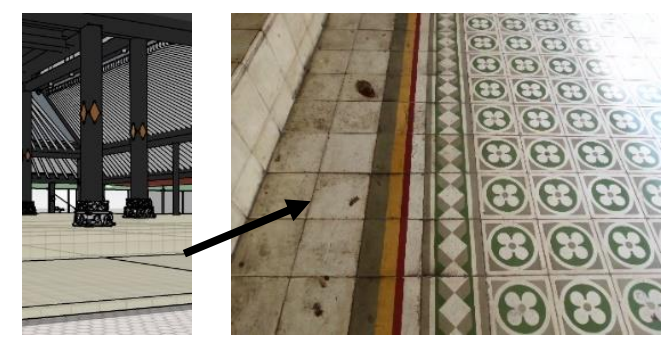

Figur 10. Gambar dan Pola Lantai Bangsal Sri Manganti (Sumber: Dokumen Pribadi, November 2016)

Lantai ini terbuat dari material semen yang melalui proses press dan memiliki pola bunga yang memberikan keindahan ( figur 11).

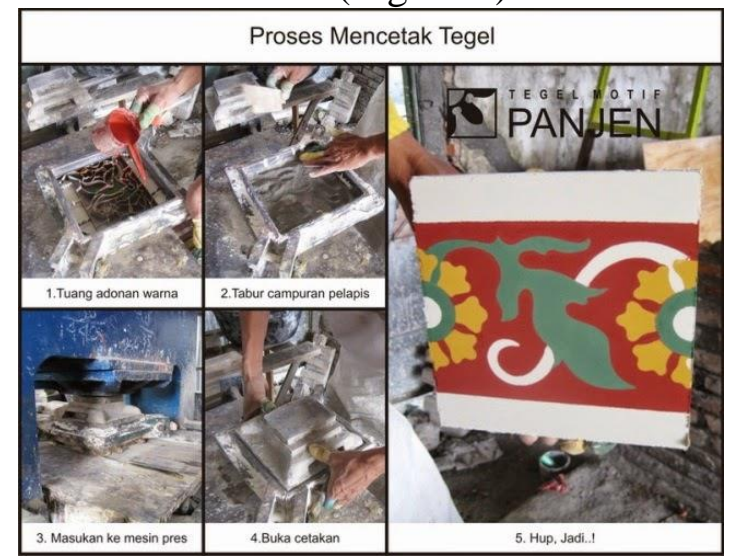

Figur 11. Proses Pembuatan Tegel Motif

(Sumber: http://tegelmotif.blogspot.co.id/, November 2016)

b. Umpak

Umpak merupakan ciri khas arsitektur Jawa. Pada Bangunan Jawa, umpak berfungsi sebagai pondasi yang menahan beban bangunan. Sebagian besar bangunan Jawa di Keraton memiliki bagian umpak yang dihiasi dengan hiasan Padma (gambar 10.). Hiasan ini merupakan salah satu desain lokal khas daerah Yogyakarta. Kini, hampir di seluruh bagian di Yogyakarta dihiasi oleh hiasan umpak ini.

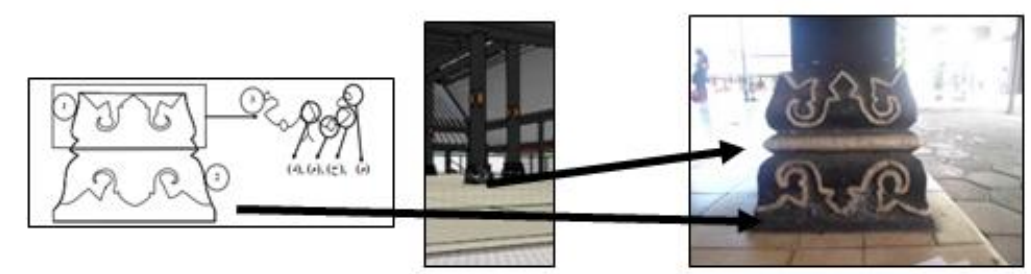

Figur 12. Motif Padma pada Umpak Bangsal Sri Manganti

(Sumber: Dokumen Pribadi, November 2016)

Material yang digunakan untuk umpak ini adalah batu alam keras yang berwarna hitam memiliki bentuk segi empat. Batu ini berasal dari Gunung Merapi dan memiliki kekuatan yang baik. Umpak ini menggunakan sistem umpak untuk menyangga tiang.

c. Kolom

Kolom pada bangunan utama Bangsal Sri Manganti terdiri kolom persegi dan kolom berpenampang bulat. Warna dari struktur utama bangunan adalah abu tua dan dihiasi dengan warna kontras merah dan emas pada bagian tengah, dengan tujuan untuk memperindah dan memberikan kesan penting. Hal ini dikarenakan tiang pada 
Bangsal Sri Manganti besar dan tinggi, sehingga dengan adanya ornamen pada bagian tengah akan memberikan kesan yang lebih pendek (figur 13).
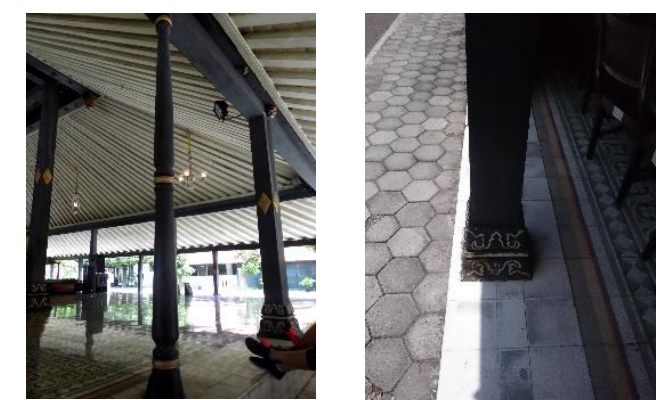

Figur 13. Kolom pada Bangsal Sri Manganti

(Sumber: Dokumen Pribadi, November 2016)

Ornamen yang terdapat pada kolom bangunan adalah bentuk wajikan yang merupakan ragam hias unsul flora. Hal ini memberikan keunikan pada kolom. Pada bagian kolom bulat pada bagian tengah terdapat ornamen ring yang disusun secara indah dan proporsional (figur 14).
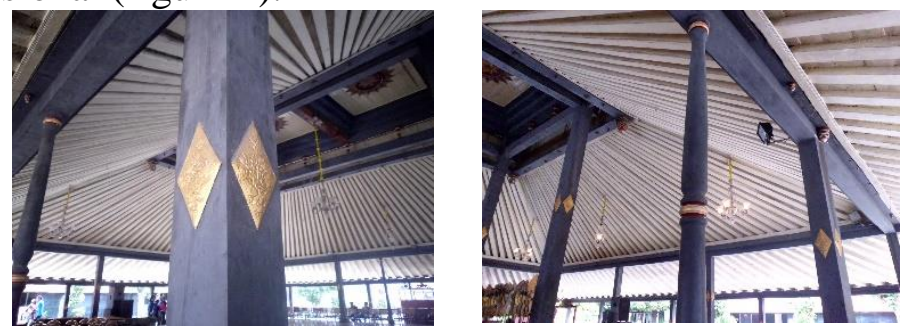

Figur 14. Ornamen Wajikan dan Ring pada Kolom Kayu

(Sumber: Dokumen Pribadi, November 2016)

\section{d. Balok}

Balok merupakan bagian yang menyalurkan beban atap pada kolom. Pada bangsal ini juga terdapat 2 jenis balok, yakni balok induk dan balok anak, dimana balok induk diberi warna hitam, sedangkan balok anak diberi warna putih. Pada balok terdapat ornamen nanasan. Ragam hias nanasan ini merupakan simbol buah, yang serupa dengan buah nanas yang penuh duri. Bentuk ini melambangkan bahwa untuk mendapat sesuatu yang diinginkan, harus mampu mengatasi rintangan yang penuh duri. Ornamen ini memberi keindahan beragam hias flora pada bangunan (figur 15).

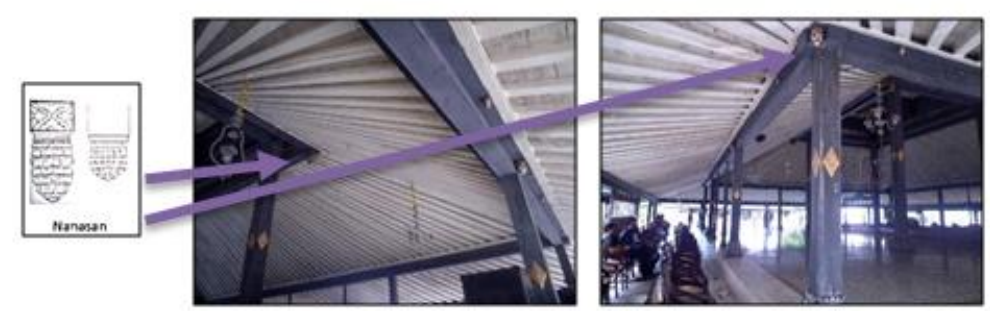

Figur 15. Balok dan Ornamen Nanasan pada Bangsal Sri Manganti (Sumber: Dokumen Pribadi, November 2016)

Balok pada Bangsal Sri Manganti disusun dengan pola radius, berbeda dengan bangunan- bangunan modern yang disusun tegak lurus satu sama lain. Balok yang disusun secara baik ini diekspos karena tidak ditutupi oleh plafon, sehingga keindahan susunan kayu jati terekspos dengan baik.

Balok pada bagian tengah bangunan diberi ornamen khusus dan berwarna merah dan emas yang menjadikan bagian di bawah area sokoguru ini merupakan area 
yang lebih penting dibandingkan dengan area sekitarnya. Ornamen ini merupakan aplikasi ragam hias sorotan (figur 16). Makna ragam hias ini mengandung unsur keagamaan - kepercayaan, sehingga bangunan ini memiliki nilai yang cukup tinggi. Ornamen sorotan menyimbolkan ajaran agama yang lurus seperti cahaya sorotan.

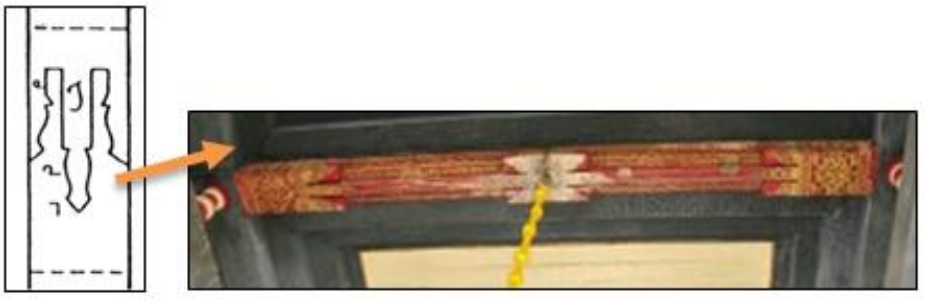

Figur 16. Balok Tengah pada Bangsal Sri Manganti

(Sumber: Joglo: Arsitektur Rumah Tradisional Jawa, 1993 dan Dokumen Pribadi, November 2016)

e. Plafon

Bagian utama Bangsal Sri Manganti, yang terletak diantara ke -empat sokoguru memiliki plafon yang terbentuk persegi panjang dan terdiri dari susunan kayu jati, yang diberi warna krem dan memiliki ornamen matahari yang berwarna merah memberikan arti kemegahan (figur 17).
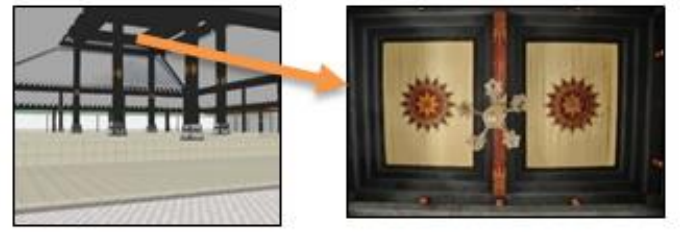

Figur 17. Plafon Utama Bangsal Sri Manganti (Sumber: Dokumen Pribadi, November 2016)

f. Wuwung dan Talang

Wuwung pada bangunan ini terdiri dari bahan seng yang berwarna merah agar memberikan aksen diantara warna gelap pada Bangsal Sri Manganti. Bentuk wuwung diakhiri dengan bagian yang naik untuk memberikan nilai estetika. Diantara Bangsal Sri Manganti dan selasar terdapat talang horizontal berwarna putih dan talang vertikal berwarna hijau tua (figur 18).
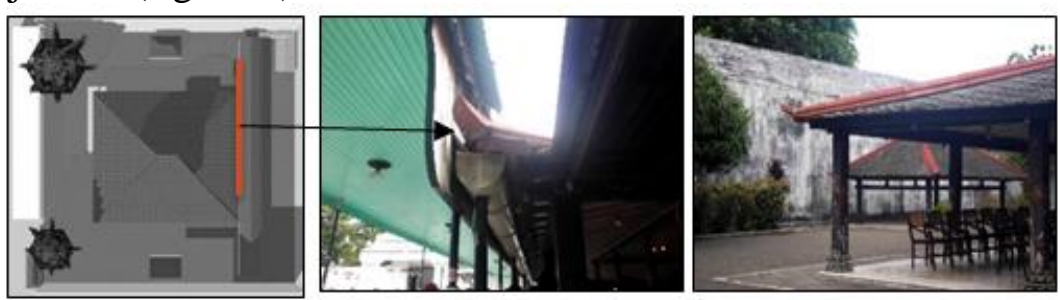

Figur 18. Wuwung Seng pada Bangsal Sri Manganti (Sumber: Dokumen Pribadi, November 2016)

\section{g. Atap}

Bangsal Sri Manganti memiliki penutup atap berbentuk perisai dengan penutup yang terbuat dari material bitumen. Atap joglo ini merupakan bentuk asli arsitektur Jawa (figur 19).। 


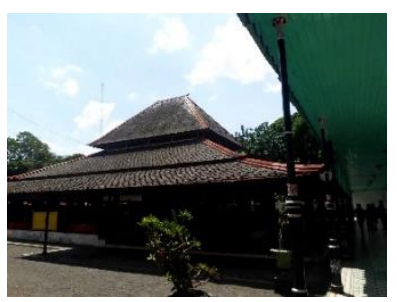

Figur 19. Atap pada Bangsal Sri Manganti

(Sumber: Dokumen Pribadi, November 2016)

Bangsal Sri Manganti memiliki 3 susun atap, yakni: atap penitih, atap penganggap, dan atap brunjung (figur 20). Rumah Jawa akan semakin tinggi tingkatannya ketika memiliki semakin banyak susunan tingkat atap
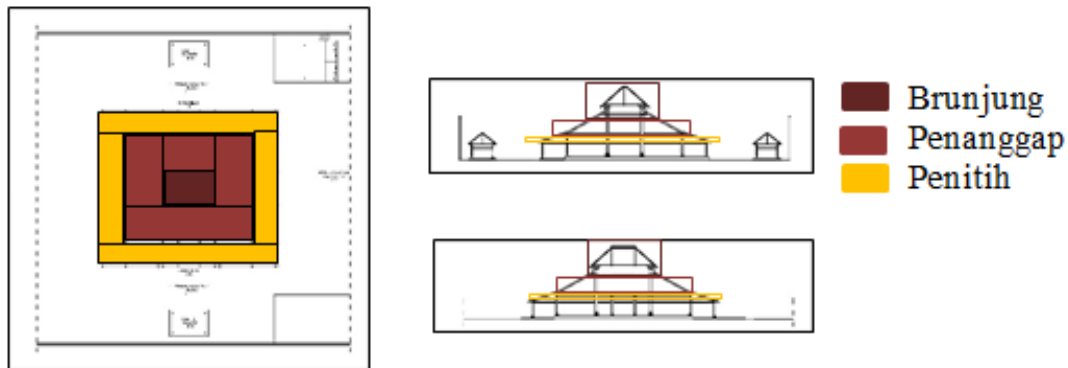

Figur 20. Atap Susun 3 pada Bangsal Sri Manganti

(Sumber: Dokumen Pribadi, November 2016)

\subsection{PENILAIAN PADA PENAMBAHAN ELEMEN BANGUNAN YANG DIJADIKAN PEDOMAN PERIODISASI}

Pada periode kepemimpinan Sultan Hamengkubuwono VIII, Bangsal Sri Manganti telah mengalami beberapa perubahan yang lebih beradaptasi dengan lingkungan tropis. Penambahan elemen juga disesuaikan dengan nilai yang terkandung di dalam Kompleks Keraton Yogyakarta. Hal ini akan menjadikan bangunan ini memiliki nilai guna yang lebih baik terhadap lingkungan sekitar dibandingkan dengan periode sebelumnya.

Tabel 1. Penambahan Elemen Tahun 1921- 1934

(Sumber: Dokumen Pribadi, November 2016)

\begin{tabular}{|c|c|c|}
\hline Gambar Elemen & Elemen & Penilaian \\
\hline \multirow[t]{4}{*}{ (1) } & Atap Seng & $\begin{array}{l}\text { Nilai Arsitektur: } \\
\text { Adaptasi terhadap kebutuhan } \\
\text { area selasar yang beratap. } \\
\text { Langgan arsitektur tropis } \\
\text { dengan bentuk pelana. }\end{array}$ \\
\hline & Struktur besi tuang & $\begin{array}{l}\text { Nilai Arsitektur: } \\
\text { Elemen dekoratif pada tiang } \\
\text { besi bergaya pola floral. }\end{array}$ \\
\hline & Plafond PVC & $\begin{array}{l}\text { Penggunaan warna hijau yang } \\
\text { sesuai dengan warna keraton. }\end{array}$ \\
\hline & $\begin{array}{lr}\text { Dinding } & \text { pengisi } \\
\text { PVC } & \text { dengan } \\
\text { bingkai kayu }\end{array}$ & $\begin{array}{l}\text { Penggunaan warna hijau yang } \\
\text { sesuai dengan warna keraton. } \\
\text { Juga penggunaan elemen } \\
\text { dekorasi floral pada dinding. }\end{array}$ \\
\hline
\end{tabular}




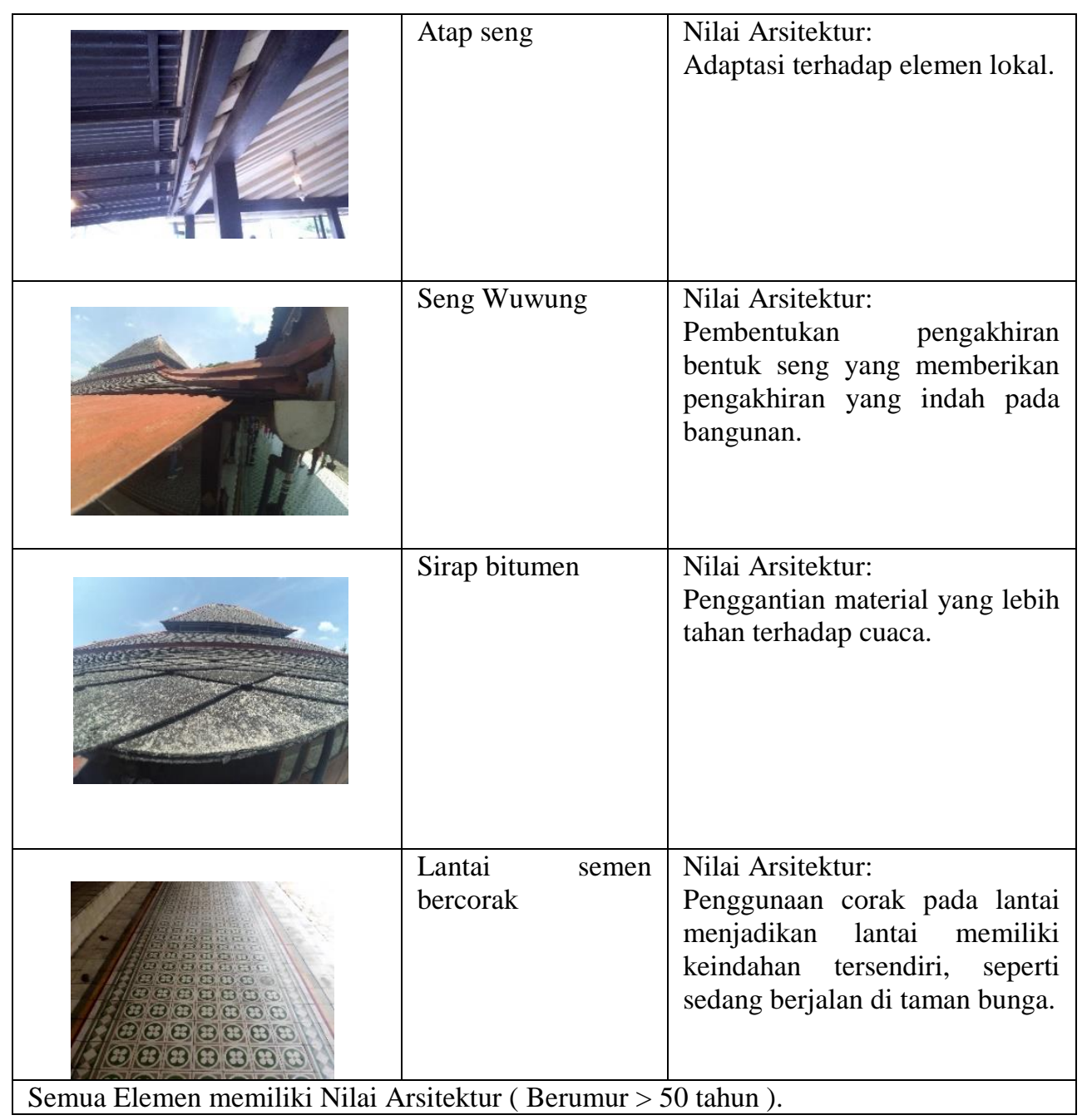

\subsection{TINDAKAN KONSERVASI BANGSAL SRI MANGANTI}

Ketika dilihat dari jenis- jenis kerusakan pada komponen bangunan, namun dengan tetap memperhatikan kesesuaiannya dengan penetapan periode acuan konservasi, maka dilakukan dua jenis tindakan yakni: tindakan adaptasi dan tindakan preservasi.

\section{Tindakan Adaptasi Bangsal Sri Manganti}

Tindakan adaptasi penggunaan material transparan pada dinding tambahan. Sesuai dengan kebutuhan fungsi yang membutuhkan penyekat ruang. Material transparan akan memberikan batas namun tidak mengganggu secara visual ( figur 22).
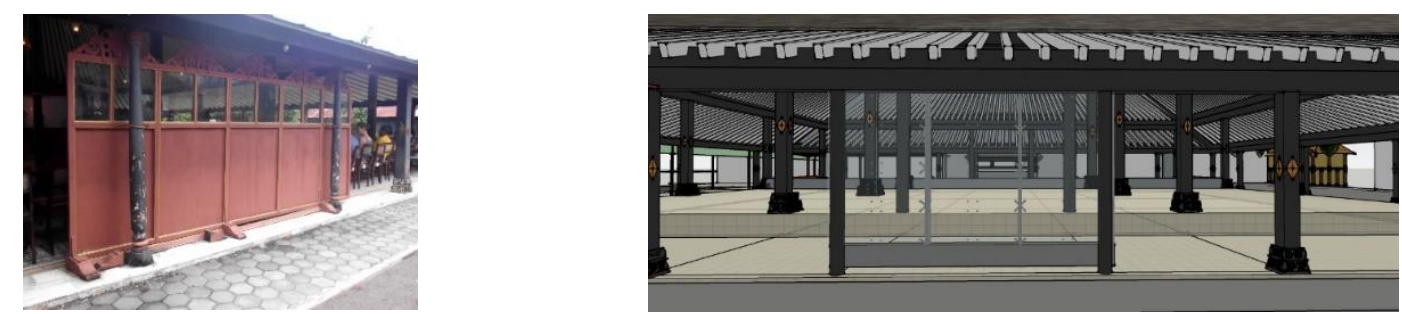

Figur 21. Perubahan Material Dinding Masif Menjadi Transparan (Sumber: Dokumen Pribadi, November 2016 
Tata ruang Bangsal Sri Manganti memiliki orientasi utara ke selatan. Pada bagian utara untuk publik dan selatan untuk para abdi dalam Keraton. Tata ruang ini tetap dipertahankan dari dulu hingga sekarang. Pada bagian selatan bangunan terdapat selogilang yang berharga Karena merupakan area untuk Sultan. Namun ternyata kurangnya kepekaan menjadikan selogilang ini tidak terlihat begitu berharga, oleh Karena itu diperlukan suatu batas yang menandakan bahwa selogilang ini merupakan area yang memiliki fungsi penting. Area ini tertutupi oleh adanya penempatan gamelan di sekelilingnya. Oleh karena itu ada baiknya untuk memberikan jarak dan pembatas( figur 22).

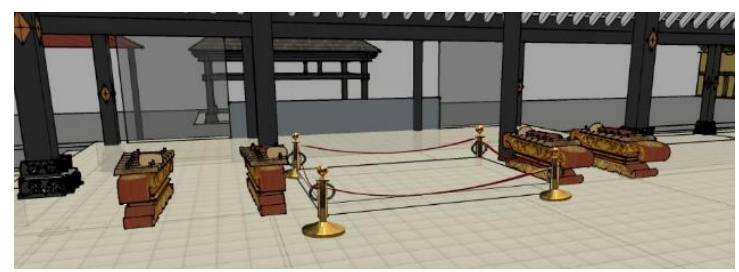

Figur 22. Pembatas di Sekitar Selogilang (Sumber: Dokumen Pribadi, November 2016)

Pencahayaan buatan yang dipergunakan untuk memberikan kesan indah dan tertata untuk pertunjukkan kesenian telah dimiliki oleh Bangsal Sri Manganti. Hal ini menjadikan Bangsal Sri Manganti sudah benar- benar disiapkan sebagai Area Pertunjukkan. Hal yang perlu diperhatikan adalah perawatan lampu- lampu tersebut. Lampu gantung yang memberikan kesan estetika yang baik, tampaknya sudah kotor, sehingga diperlukan perawatan yang rutin untuk menjaga kualitas keindahan pencahayaan tersebut (figur 23).
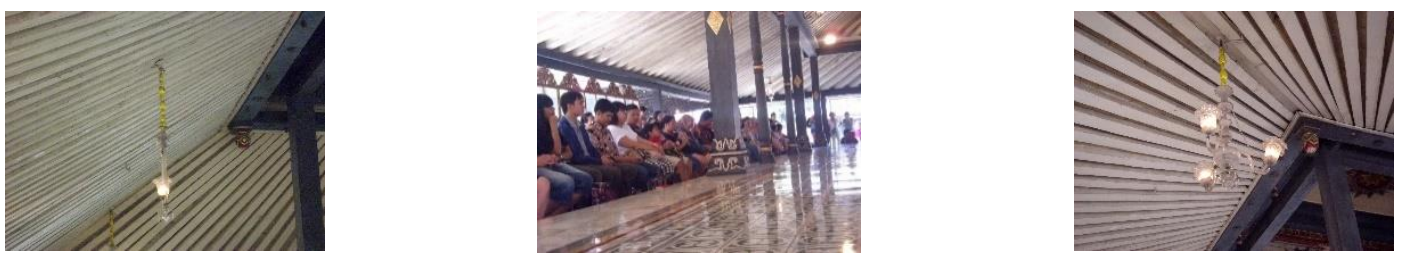

Figur 23. Kondisi Pencahayaan Buatan pada Bangsal Sri Manganti (Sumber: Dokumen Pribadi, November 2016)

Suhu pada saat berada di dalam Bangsal Sri Manganti cukup tinggi yakni diatas 30 ${ }^{\circ} \mathrm{C}$, namun nampaknya penggunaan material yang menginsolasi panas, dan juga adanya cross ventilation menjadikan suasana di dalam Bangsal Sri Manganti tetap nyaman. Oleh karena itu, suasana keterbukaan harus tetap dipertahankan dengan tidak menggunakan dinding partisi di sekeliling bangunan.

\subsection{Tindakan Preservasi Bangsal Sri Manganti.}

Material penutup atap menggunakan sirap bitumen pada bangunan utama dan seng pada bangunan tambahan. Kini, nampaknya sirap bitumen sudah jarang dipakai di kompleks Keraton Yogyakarta karena beban yang cukup berat, dan bila terjadi retak akan sulit untuk diintefikasi, sehingga menyebabkan bocor pada bangunan. Oleh karena itu seharusnya sirap bitumen diganti dengan sirap asbes yang baru (adaptasi). Pergantian bahan diijinkan dengan pertimbangan konservasi, namun tetap mempertahankan bentuk yang digunakan, yakni bentuk lei (preservasi). Agar menjadikan sirap asbes menjadi lebih awet, maka dilapisi lapisan anti air( figur 24). 


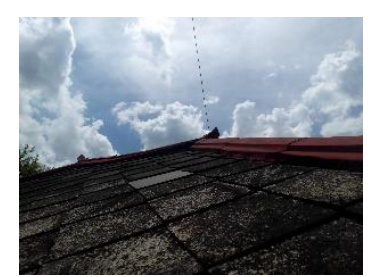

Figur 24. Sirap Bitumen yang mengalami Keretakan di beberapa bagian.

(Sumber: Dokumen Pribadi, November 2016)

Atap Seng. Bangsal Sri Manganti mengalami penambahan atap seng pada bagian utara, timur, dan selatan. Namun kekurangan dari atap seng ini nampaknya menimbulkan karat yang cukup terlihat, oleh karena itu perlu dilakukan pengecatan ulang dan pelapis anti air sehingga dapat bertahan lebih lama. Bila kondisi seng sudah mengalami kebocoran, lebih baik diganti dengan atap seng yang baru (figur 25).

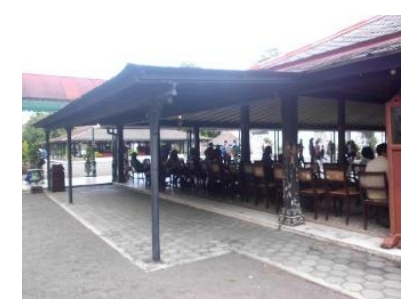

Figur 25. Atap Seng pada Elemen Tambahan (Sumber: Dokumen Pribadi, November 2016)

Balok kayu jati. Balok pada Bangsal Sri Manganti terbuat dari kayu jati. Meskipun terbuat dari kayu jati yang konon katanya anti serangga, namun kayu ini sudah mengalami kerusakan di beberapa bagian. Pada bagian atas yang tidak terkena air hujan dan panas, ternyata terdapat kebolongan di beberapa bagian yang diakibatkan oleh serangga (figur 26).

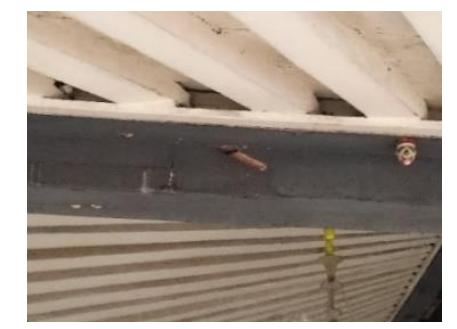

Figur 26. Kerusakan pada Balok Utama Bangunan

(Sumber: Dokumen Pribadi, November 2016)

Jenis serangga yang terdapat pada bangunan adalah yang membuat lubang yang cukup besar,yakni serangga pengebor kayu, oleh karena itu upaya pembersihan kayu dari serangga cukup mudah. Cara yang harus diraih adalah dengan menghilangkan bibit serangga pada kayu tersebut dengan semprotan bertekanan, lalu dibersihkan telur- telurnya dengan menggunakan sikat halus.

Berdasarkan kondisi elemen - elemen kayu yang kropos karena terserang oleh rayap, perlu segera dikonservasi ( sumber: hasil penelitian tekno arkeologis, PT Kerta Gana Yogyakarta).

Cara penanganannya adalah:

1. Lubang- lubang kayu yang termakan serangga dikorek dan dibersihkan.

2. Lubang disterilkan dengan injeksi Dieldrin $80 \mathrm{WP}$ kadar $3 \%$.

3. Ditutup dengan bahan campuran Araldite LY 560 dengan dempul kayu. 
Selain diakibatkan oleh serangga, ternyata balok kayu pada bagian pertemuan dengan balok lainnya juga lembab dan ditumbuhi jamur (figur 27).

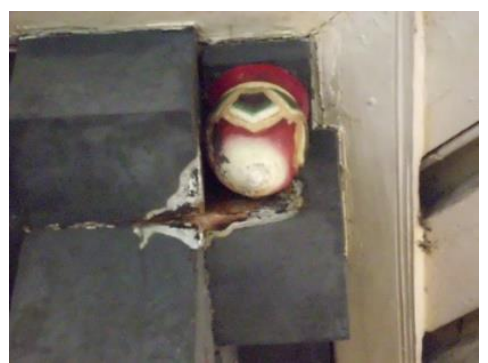

Figur 27. Bagian Balok yang Ditumbuhi Jamur (Sumber: Dokumen Pribadi, November 2016)

Kerusakan elemen kayu yang disebabkan oleh air yang masuk dari sela- sela sambungan kayu dan menyebabkan kayu menjadi lembab. Cara untuk menghindari kerusakan karena penyerapan air adalah dengan cara:

1. Kayu dikeringkan terlebih dahulu.

2. Melapisi kayu dengan bahan Paraloid B.27 dengan kadar 5-10\% ke dalam pelarut Tuluol.

Pengolesan Paraloid B.27 bertujuan untuk menghindari keretakan kayu dan merupakan bahan konsolidasi kayu.

Kolom kayu jati. Kolom kayu jati pada Bangsal Sri Manganti bagian dalam memiliki kualitas yang baik, namun pada bagian terluar bangunan telah mengalami kerusakan. Hal ini disebabkan kayu pada bagian luar langsung berinteraksi dengan air hujan dan panas matahari. Hal ini dikarenakan pendeknya teritis yang dimiliki oleh bangunan ini. Diperlukan adanya pelapisan yang tahan terhadap air dan matahari untuk menjaga kualitas kolom kayu pada bangunan ini( figur 28).

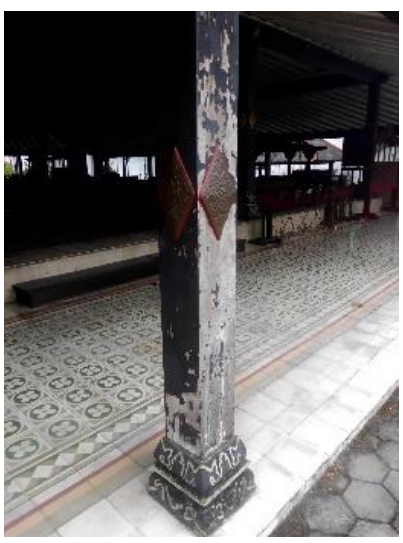

Figur 28. Kerusakan pada Kolom Terluar Bangsal Sri Manganti (Sumber: Dokumen Pribadi, November 2016)

Peralatan yang harus disiapkan di dalam melakukan pengelupasan cat adalah kuas dan kertas, alat pengikis cat, dan heat gun ( alternatif). Langkah- langkah stripping pada material kayu:

1. Membersihkan permukaan dengan menggunakan lap bersih serta air secukupnya kemudian keringkan.

2. Mengoleskan zat pengelupas/ stripper dengan menggunakan kuas yang lembut, cat akan terkelupas membentuk gumpalan- gumpalan cat yang kasar.

3. Hilangkan sisa- sisa cat yang masih menempel pada perukaan kayu dengan pengikis cat. 
4. Ulangi langkah- langkah di atas hingga seluruh cat bisa terkelupas dari permukaan kayu.

5. Mengecat kembali kayu yang sudah selesai melalui proses stripping.

Kolom besi tuang. Kolom besi tuang mengalami perubahan yang sangat drastis. Hal ini terlihat dari warna yang cepat memudah dan timbul karat di sela- sela cat dari tiang besi. Hal ini karena kurangnya kesesuaian besi tuang pada iklim tropis. Perlu dilakukan pelapisan yang lebih rutin dan harus dipastikan menutupi seluruh bagian dengan baik, sehingga tidak menimbulkan kontak yang menyebabkan korosi (figur 29). Sebelum dilakukan pengecatan pada besi harus dilakukan proses stripping terlebih dahulu.

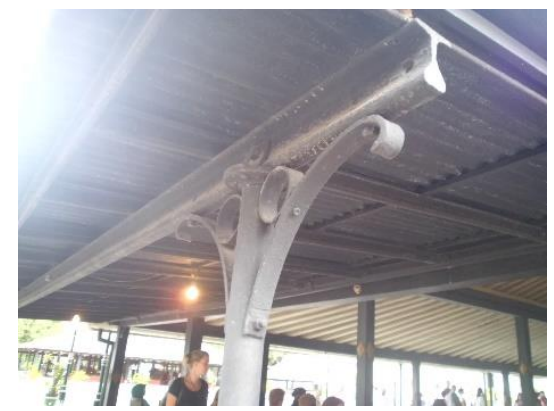

Figur 29. Kerusakan pada Kolom Besi Tuang Bangsal Sri Manganti (Sumber: Dokumen Pribadi, November 2016)

Batu Merapi. Batu pada Bangsal Sri Manganti merupakan jenis batu metamorfotis yang berasal dari pegunungan. Oleh karena itu pada dasarnya bagian umpak sudah tahan terhadap tekanan dari lingkungan sekitar, namun batu ini memiliki pori, sehingga diperlukan kebersihan untuk menjaga kualitas umpak ini.

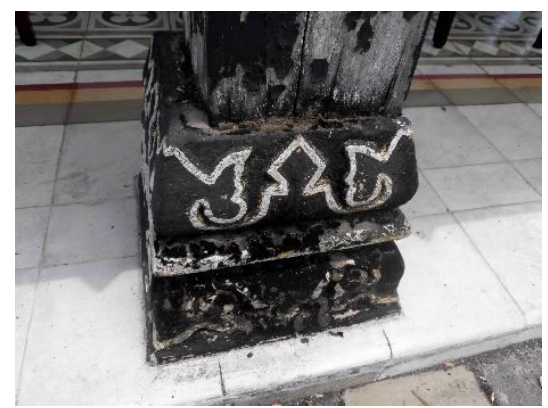

Figur 30. Keropos dan Retak pada Umpak (Sumber: Dokumen Pribadi, November 2016)

Jika terjadi keropos pada batu (figur 30), dapat dilakukan tambalan dengan jenis batu yang serupa dan ditempel dengan mortar atau dengan semen hidrolik. Hal ini disebabkan semen hidrolik memiliki kemampuan untuk mengikat dan mengeras di dalam air. Pada bagian yang retak, sebelum diberi semen hidrolik permukaannya harus dibersihkan terlebih dahulu. Setelah itu gosokkan semen pada bagian yang retak secara berulang- ulang hingga permukaan yang retak rata dengan permukaan yang tidak mengalami keretakan.

Umpak pada Bangunan Jawa memiliki ragam hias, salah satunya ragam hias Padma. Untuk menjaga keutuhan bentuk ragam hias yang telah hilang pada beberapa bagian, digunakan metode cetakan bekisting yang mengikuti pola bentuk Padma, sehingga ragam hias tersebut tetap terjaga (figur 31). Bagian umpak yang mengalami keropos diganti oleh semen hidrolik agar umpak kembali ke bentuk semula. 


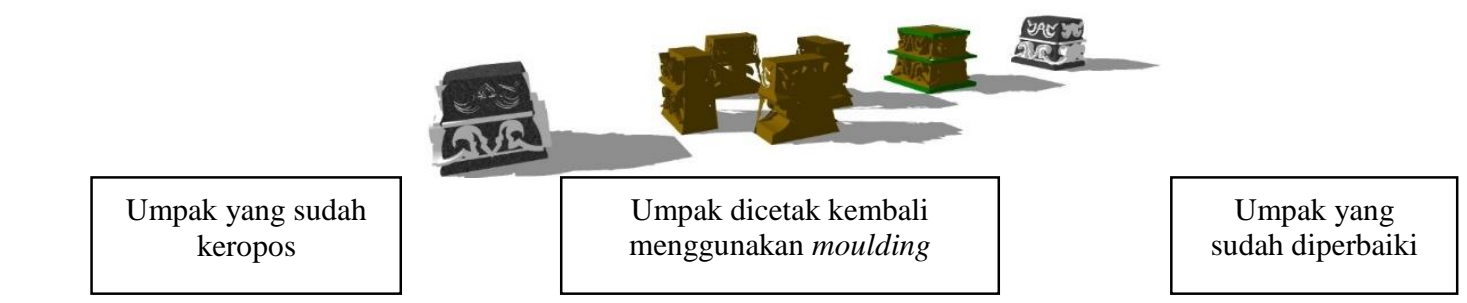

Figur 31. Cara Pembuatan Ragam Hias dengan Menggunakan Bekisting

(Sumber:http://kontruksibangunan-kb1.blogspot.co.id/2013/03/cara-menghitung-volume-bekisting-kolom.html dan Dokumetasi Pribadi, Desember 2016)

\section{PENUTUP}

\subsection{KESIMPULAN}

Bangsal Sri Manganti memiliki makna kultural. Hal ini menjadikan Bangsal Sri Manganti memiliki keistimewaan. Nilai- nilai yang terkandung di dalam Bangsal Sri Manganti adalah nilai arsitektural, nilai estetika, dan nilai guna bangunan

Bangsal Sri Manganti memiliki nilai arsitektural Bangunan khas Jawa, yaitu Joglo Mangkurat dengan struktur Lambang Gantung, yang terdiri dari elemen garis dan bidang dengan warna dominan abu tua. Bentuk bangunan yang unik ini menjadi dasar penilaian arsitektural dari bangunan ini. Selain hal tersebut, material yang merupakan bahan bangunan untuk membangun sebuah bangunan merupakan material asli dari Yogyakarta. Komponen bangunan yang terdiri dari umpak batu, lantai semen, tiang kayu jati, ander dan molo, serta atap merupakan bagian terpenting penyusun Bangsal Sri Manganti. Namun karena perlunya penyesuaian terhadap iklim tropis yang memerlukan adanya selasar tertutup, akhirnya berdasarkan pertimbangan terhadap lingkungan sekitar, ditambahkanlah elemen selasar yang menempel pada Bangsal Sri Manganti. Hal ini dilakukan karena merupakan respon terhadap lingkungan.

Bangsal Sri Manganti memiliki nilai estetika yang terdapat pada ragam hias yang berada pada elemen arsitekturnya. Ragam hias Padma terdapat pada bagian umpak, ragam hias bunga terdapat pada bagian lantai, ragam hias wajikan berada pada bagian tiang, ragam hias nanasan dan sorotan pada bagian molo ( balok ), dan juga simbol matahari pada bagian tengah Bangsal Sri Manganti. Ragam hias pada bagunan ini mayoritas termasuk ke dalam ragam hias unsur floral yang memberikan keindahan pada bangunan. Selain itu terdapat ragam hias matahari dan sorotan pada bagian yang paling sakral di bangunan ini, yakni pada bagian tengah.

Nilai guna bangunan ini nampaknya telah mengalami pergeseran dari tempat untuk mengunggu panggilan dan Sultan menerima tamu hingga kini menjadi tempat pertunjukan sehari- hari di Keraton Yogyakarta. Nampaknya perubahan ini menambah nilai bangunan di tengah- tengah masyarakat umum.

Bangsal Sri Manganti telah berdiri cukup lama, hal ini menjadikan beberapa bagian telah mengalami kerusakan. Di bawah ini akan dibahas mengenai kondisi dan penyebab kondisi elemen Bangsal Sri Manganti saat ini.

Kondisi elemen- elemen pada Bangsal Sri Manganti sudah mengalami beberapa penurunan mutu. Warna umpak telah menjadi pudar yang diakibatkan oleh debu dan kurangnya perawatan, selain itu terdapat sedikit keretakan pada bagian umpak. Lantai semen bercorak telah menjadi kotor dan retak pada beberapa bagian karena mengalami beberapa gesekan dengan benda lainnya. Kolom dan balok kayu jati telah mengalami pengelupasan dan lubang di beberapa bagian karena efek air hujan, matahari, dan juga serangga yang 
mengkonsumsi kayu tersebut. Atap yang telah mengalami keretakan di beberapa bagian karena material sudah lama tidak mengalami penggantian dan juga beban air hujan yang mengenai material atap.

Oleh karena itu diperlukan tindakan konservasi yang tepat, yakni: tindakan konservasi adaptasi dan preservasi. Kedua tindakan ini termasuk kepada tindakan yang cukup ringan dilaksanakan pada Bangunan yang dikonservasi. Bangsal Sri Manganti termasuk ke dalam bangunan penting di dalam Keraton Yogyakarta.

Kurangnya perawatan pada elemen -elemen bangunan menjadikan penurunan mutu pada elemen tersebut. Oleh karena itu perlu dilakukan pembersihan, pengecatan, dan pelapisan pada bagian umpak dan kayu yang sudah mengelupas. Pada bagian lantai dilakukan perubahan jenis kursi yang akan memberikan dampak minimal terhadap lantai. Pada bagian kolom dan balok yang digerogoti serangga harus dilakukan penanganan khusus dengan obat dan kombinasi dengan injeksi cairan anti serangga pada bagian yang bolong. Pada bagian atap hendaknya dilakukan penggantian material dengan material yang lebih ringan dan dipakai oleh bangunan lain di dalam Keraton, karena material yang dipakai berat, telah retak dan pecah di beberapa bagian yang akan menimbulkan kebocoran.

\subsection{SARAN}

Perawatan terhadap elemen bangunan sebaiknya dilakukan secara rutin dan mendetail. Hal ini ditujukan agar bagian yang tidak terjangkau seperti plafond an langit- langit yang cukup tinggi dapat menjadi perhatian sehingga dapat dibersihkan. Perawatan, berupa pembersihan Bangsal cukup dilakukan 1 bulan sekali. Perlu dilakukan pemeriksaan terhadap elemen- elemen, seperti misalnya bagian penutup atap sirap sehingga tidak menimbulkan keborocan. Proses pemasangannya pun harus dipantau dan ditest, sehingga hasilnya tidak mengecewakan.

Pada elemen- elemen yang sedang mengalami kerusakan, seperti contohnya kolom yang mengelupas dan berlubang, juga balok yang digerogoti serangga sebaiknya dilakukan perbaikan, sehingga tidak mengalami penurunan mutu yang dapat menyebabkan kerusakan permanen pada Bangsal Sri Manganti.

Penambahan elemen- elemen pada bangunan harus lebih diperhatikan, seperti contohnya dinding tambahan. Penambahan tersebut sebaiknya tidak menutupi bangunan awal tersebut. Penggunaan material transparan dapat menjadi alternatif penggunaan bahan. Jika terdapat penambahan struktur baru harus tetap memperhatikan dan mempertahankan kondisi kekuatan struktur lama

\section{DAFTAR PUSTAKA}

Orbasli, Aylin. (2008). Architectural Conservation. Oxford, UK: Blackwell Publishing Company.

Feilden, Bernard M. (1994). Conservation of Historic Buildings. Oxford: Butterworth Heinemann Ltd.

Forsyth, Michael. (2007). Structures \& Construction in Historic Building Conservation. Oxford, UK: Blackwell Publishing Ltd.

Forsyth, Michael. (2008). Material \& Skills for Historic Building Conservation. Oxford, UK: Blackwell Publishing Ltd.

Sombu, Alwin, 2012. Pelestarian Arsitektur Museum Sonobudoyo Yogyakarta 
Gubernur Daerah Istimewa Yogyakarta. 2013. Peraturan Gubernur Daerah Istimewa Yogyakarta Nomor 62 tahun 2013. Yogyakarta: Gubernur Daerah Istimewa Yogyakarta.

Ismunandar, R.K. (1993). Joglo, Arsitektur Rumah Tradisional Jawa. Semarang: Dahara Prize.

Kridosasono, R. Slamet S. (1976). Kawruh Kalang (Ilmu Pertukangan Kayu/Membuat Rumah Kayu). Surakarta: Museum Radya Pustaka

Pemerintah Provinsi Daerah Istimewa Yogyakarta. 2012. Peraturan Daerah Provinsi Daerah Istimewa Yogyakarta Nomor 6 Tahun 2012 Tentang Pelestarian Warisan Budaya dan Cagar Budaya. Yogyakarta: Pemerintah Provinsi Daerah Istimewa Yogyakarta.

Undang-Undang Republik Indonesia Nomor 11 Tahun 2010 Tentang Cagar Budaya

Swastikawati, Ari. 2014. Upaya Penanganan Kayu Secara Tradisional; Studi Kasus : Tradisi Masyarakat Kabupaten Parigi Moutong Provinsi Sulawesi Tengah. Buletin Kemdikbud.

Wiryatmaja, Sutadi. (1986). Pengetahuan Bangunan Rumah Tradisional Jawa (Pengetahuan Kalang). Surakarta: Departemen Pendidikan dan Kebudayaan Direktorat Jendral Kebudayaan Proyek Penelitian Dan Pengkajian Kebudayaan Nusantara (Javanologi) 